\title{
Community Health Workers Working the Digital Archive: A Case for Looking at Participatory Archiving in Studying Stigma in the Context of HIV and AIDS
}

\author{
by Naydene de Lange and Claudia Mitchell \\ Nelson Mandela Metropolitan University; McGill University \\ Sociological Research Online, 17 (1) 7 \\ <http://www.socresonline.org.uk/17/1/7.html> \\ $10.5153 /$ sro. 2591
}

Received: 1 Sep 2011 Accepted: 18 Jan 2012 Published: 28 Feb 2012

\begin{abstract}
Addressing the issue of HIV-stigma is recognised as essential to reducing the spread of HIV and AIDS, enabling community members to access prevention, treatment and care. Often the very people who are able to contribute to solving the problem, are marginalised and do not see ways to insert themselves into dialogues related to combating stigma. Community health workers in rural South Africa are one such group. At the heart of the research discussed in this article is an intervention based on participatory analysis through participatory archiving (Shilton and Srinivasan 2008). Drawing on participatory work with thirteen community health workers in rural KwaZulu-Natal, we use a digital archive containing HIV-stigma visual data - generated five years earlier by youth in the community - to engage the participants in the analysis. Drawing on such participatory work as Jenkins' participatory cultures framework, we focus on the idea of reusing, re-coding, and re-mixing visual data. One participant stated that "these pictures talk about the real issues faced by our communities", highlighting the value of resources generated by community members themselves. They also indicate that they "could use [the resources] to teach the cons of stigmatising". A key concern in work related to visual images (particularly in projects such as ours where a large amount of visual data is produced) is to consider ways of extending its life through the use of community-based digital archives.
\end{abstract}

\section{Keywords: Community Health Workers; Community-Based Digital Archive; Participatory Archiving; Participatory Cultures; Stigma; HIV and AIDS}

\section{Introduction}

1.1 The high incidence of HIV and AIDS has rendered communities, particularly rural communities in South Africa, vulnerable in various ways. In one community in the province of KwaZulu-Natal where we have been working for the last six years with young people, teachers, community health workers and parents, young people remain at high risk to HIV infection. ${ }^{[1]}$ There is a gendered face to the situation, with more than half of the young women in this rural district infected by the age of 24 (Abdool Karim 2010). While there are many different initiatives across health, education, and social development to address the issues, one of the areas that we regard as critical is bringing together the various groups (such as teachers and community health workers) to 'learn together' how to address the vulnerabilities of young people in relation to HIV and AIDS. In one of our first research engagements in the community, where teachers and community health workers participated in a photovoice ${ }^{[2]}$ activity which entailed taking photographs of challenges and solutions in addressing HIV and AIDS, we saw firsthand some of the benefits of 'learning together'. We noted, for example that community health workers seemed more confident than teachers to engage the youth in the community in addressing their vulnerability to AIDS. We observed how community health workers were able to address the questions and concerns the youth raised in a matter-of-fact way with appropriate information. Teachers said that they sometimes felt that they could not really address the issues in the classroom and acknowledged, that at times, they did not actually have the information that young people were seeking. At the same time, because of their up close knowledge of young people in the school setting, they were able to identify some of the challenges in their day-to-day interactions with young people. In particular they highlighted that HIV-related stigma was a critical issue that needed to be addressed more directly with young people, and they wondered if young people (and the community more broadly) might benefit from participating in a 
1.2 For our research team, this suggestion was important for two reasons. First, the teachers' idea to use photovoice with the students highlights the ways in which a methodology such as photovoice which was brought in 'from the outside' was identified by the community itself as something that might be of value in addressing critical issues. The second reason why their suggestion was so important is that the teachers were the ones who were identifying stigma as the issue that they thought needed to be addressed.

1.3 HIV-related stigma, as the teachers highlighted, is a critical issue. Communities, schools and families find it difficult to address HIV-related stigma, as HIV infections are linked to issues of sexuality, and with the stigmatisation of talking about sex in many communities, the stigmatisation of those infected with HIV is exacerbated. This contributes to the 'othering' of those who are perceived to be promiscuous (usually girls and women) or of those whose sexualities differ from conventional heterosexual normativity (Campbell et al. 2003). In the school in the rural community where we have been working, the teachers would have been aware of 'enacted' stigma, referring to behaviour such as judging, labelling, gossiping, verbally and physically abusing, stereotyping, avoiding, excluding, rejecting, and discriminating (Simmonds \& Coomber 2009; Bhana 2008; Dlamini et al. 2007) - towards infected students because of being "branded" (Chitando \& Togarasei 2008:5), and hence their request to address stigma with their students. The teachers would also have been aware of 'associated stigma' referring to the poor treatment of and avoidance of contact with any of the family members, in this instance the students, whose parents or siblings were infected (Goodall et al. 2011; Greeff et al. 2008:102; Holzemer et al. 2007). The teachers themselves might have experienced internal ("felt") stigma as infected or affected persons, displayed as negative perceptions of self and self-stigmatising behaviour (Gilbert $\&$ Walker, 2010), thus contributing as an active agent to the construction of stigma (Goodall et al. 2011:189). Clearly, such stigma - which according to Goffman (1963), is deeply discrediting, reduces the person from a whole person to a tainted and discounted one, not easily engaged in ordinary social interactions - is difficult to address and contributes to not making use of treatment, militating against HIV and AIDS intervention programmes, particularly in a small rural community (See also The Three Letter Plague by Steinberg 2008). Although stigma has been studied across a wide range of areas, such as mental health, criminality, illicit drug use, and so on (Simmonds and Coomber 2009), we can draw on these in relation to HIV-related stigma as played out in a rural community in South Africa, that has its own dynamics and challenges.

1.4 In taking up the suggestion of the teachers that we explore stigma with students, 21 Grade 8 and 9 students (nine girls and twelve boys) with an average age of 15.3, were given simple point and shoot cameras with the prompt to "Direct and take pictures of stigmatisation." They were asked to work in groups of four or five to create images, many of which drew on what we have described elsewhere as a staging process (Mitchell 2011). The groups were given approximately an hour to take their photographs. The films were developed in sepia, in preparation for the next workshop (Moletsane et al. 2007). The 125 photographs taken by the students were rich in meaning, not only to the research team but also to the young people who produced them and to the teachers and community members who had a chance to view these images in exhibitions and other presentations. One of the ways we found to expand the potential for meaning-making with this collection of photographs was to develop a digital archive, and set up possibilities for what we explore here as participatory archiving and participatory analysis. We have been particularly interested in how various groups - teachers, young people and as we explore here, community health workers - might engage with the digital archive ${ }^{3}$ containing photovoice data around issues of stigma as experienced in the communities in which they themselves live and work. Thus in this article, we explore how we might engage community health workers in working with these visual texts as a way to deepen an understanding of stigma itself and how it might have changed over the five years? At the same time we were interested in how this work might contribute towards making community health workers 'agents of community empowerment' (Schneider et al. 2008:180) through participatory analysis. Beyond this, however, we highlight the emergence of new questions that come out of working with community archives and participatory analysis. What special informed consent issues need to be developed in order to ensure that participants understand the ethical issues when they give permission to have their visual texts incorporated in a community archive? In the first part of this article we develop a conceptual framework organised around participatory analysis through participatory archiving. We then describe a participatory archiving workshop carried out with a group of 13 community health workers working with photovoice data produced by young people from the same community - and which now form part of a digital archive. ${ }^{\text {[3] }}$ We conclude with a consideration of how this work might fit into a participatory cultures framework and in so doing deepen an understanding of the role of digital media in addressing HIV and AIDS in rural areas of South Africa.

\section{Conceptualising participatory analysis in community-based research}

2.1 Our work is informed by two critical areas of participatory research, namely the work on participatory analysis through participatory archiving (see for example Shilton and Srinivasan 2008) and the work on participatory cultures (see for example Henry Jenkins et al. 2006), and in particular the idea of 're-mix' through re-coding and re-working visual data as part of a community-based digital archive. Both are located within a broader framework for addressing the growing critique of participation itself and what is often framed as "giving voice" to marginalised populations. In our previous work we examine, for example, the ethics of community-based research, and especially the ways in which the research community has often limited itself to short term 'once off' participatory projects as opposed to long term projects with communities (De Lange \& Mitchell, in press). They both also speak to the significance of method and the gaps within social research which claims to be participatory but which is often lacking in tools which make it possible to consider the 


\section{The case of the democratic or participatory archive}

2.2 Our participatory work with rural community health workers and teachers working with young people draws on the use of tools such as participatory video-making, drawing, photovoice, feminist focus groups, and participatory theatre (see for example Mitchell et al. 2005; Moletsane et al. 2007; De Lange and Stuart 2008; Mitchell and De Lange 2011; Mitchell 2011 ). As we argue in this work, the 'analytic' voices of participants may show up in various places: when they sort visual images and create captions, when they curate an exhibition, or when they select images for a website. However these various activities are often seen as 'add ons' to the work rather than central to the study, and the analysis itself is treated in ways that might be secondary to what the research team regards as analysis. Indeed, an area that is understudied in the work of participatory studies and community-based research, relates to how participants themselves contribute to making meaning of the data, although of course Mitchell Duneier's award winning book Sidewalk in which he documents the participation of the secondhand sellers on the streets of Greenwich Village study in meaning making should be taken as an example of the possibilities of participation. (Duneier 2001). Significantly, we argue that the work of participatory analysis extends the place of 'community' in community-based research and within this arena, the power to have a 'say' in relation to meaning.

2.3 In his essay Reading the archive, Sekula (1993) observes that archives are typically far from neutral. Sekula cites numerous examples of the ways in which both the content and management of archives shape what knowledge (and ultimately whose knowledge) is stored in the first place, how it is coded and categorised, how it can be retrieved, and who has access to the archive. Indeed, as Hartmann et al. (1998) note in their book The colonising camera, it is not just the camera alone but the camera as a tool within a much more complex network that constitutes the non-neutral and often colonising text. In our photovoice work with communities, the aim has been to counter this idea of the colonising camera by having community members themselves document what they see as critical issues. It is key then to ensure that archival practices (the reading/coding of the images, adding metadata, storage, access and retrieval) related to working with the data are similarly democratic in nature.

2.4 The data set used for piloting the construction of the digital archive was initiated by our work with the teachers, who, as noted above, identified the issue of stigmatisation among learners at school as a critical one. The stigma-related photographs were scanned and coded by adding metadata using Dublin Core (2008) elements. The archive was built using Greenstone Software (n.d.) but was subsequently changed to Drupal (n.d.), another content management system and content management framework, deemed more user-friendly (See Figure 1).

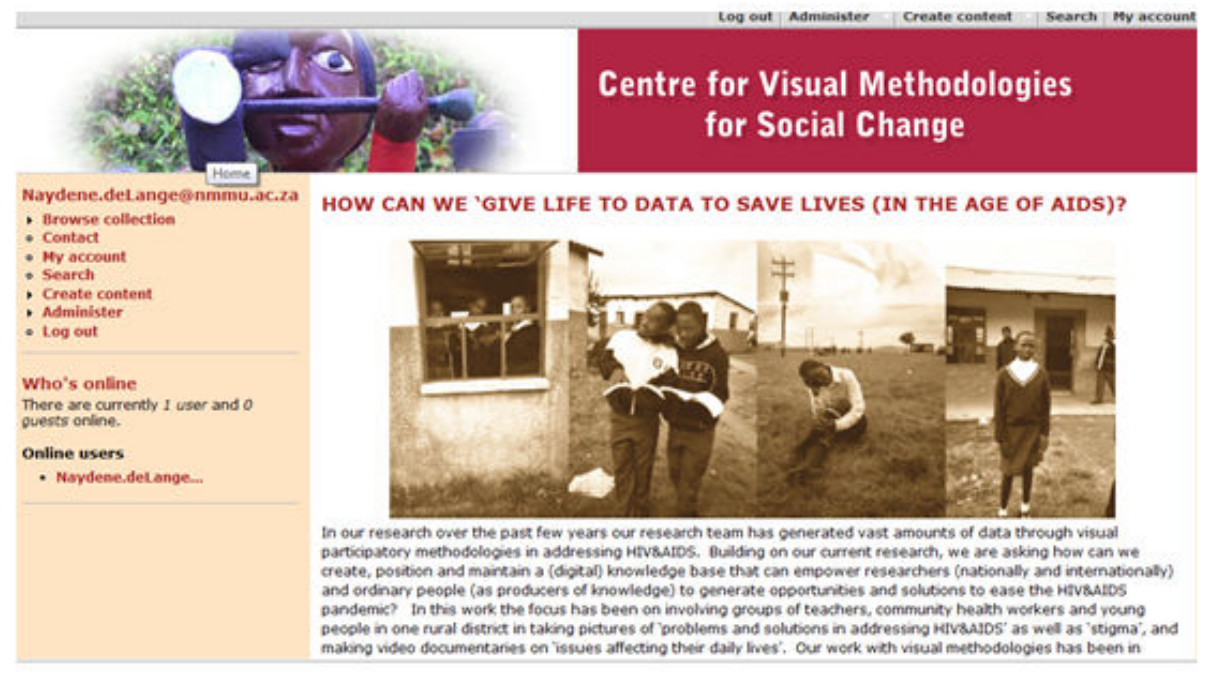

Figure 1. Screenshot of the digital archive website $<$ http://www.disa.ukzn.ac.za/cvm/>

2.5 The establishment of the digital archive paved the way for exploring the idea of participatory archiving (Huvila 2008; Shilton and Srinivasan 2008) as one type of participatory analysis where participants work with photovoice data stored in the digital archive noted above, and managed through the Centre for Visual Methodologies for Social Change at the University of KwaZulu-Natal (Mnisi et al. 2010; De Lange et al. 2010; Mitchell and De Lange 2011). The participatory archive as Huvila (2008) and Shilton and Srinivasan (2008) note, is a relatively new concept, and aims to prevent as much as possible the distortion of cultural histories of marginalised populations. This is also something highlighted in Morgan et al.'s work (2009). Creating a space and method that allows marginalised groups to become engaged in the entire archiving process allows a community to work towards creating an archive that depicts a more local representation of the community, as well as of the context of the knowledge produced. As such, the archive is then not about but rather one of the community (Hagan, cited in Shilton and Srinivasan 2008), intended to represent the analytic voices of community members, as well as to be of service to the community. 
2.6 As a research team we first developed a restricted access digital archive and then invited various groups in the community to work with the data by contributing to social tagging, adding annotations and captions, and exploring the meanings of the data in imaginative and personal ways. Teachers, for example, were further engaged by using the archive in their lessons, adding their own interpretations, and eliciting learner interpretations when using the visual data in class (Mnisi 2010). In another project in the community organised around blogging, young people worked with some of the stigma photos, and re-mixed them so that they became part of their own blogs (Mitchell et al. 2010). The project demonstrated the possibilities for re-working visual data, and in particular demonstrated possibilities for engaging young people in working with archival data. Indeed, as we documented the various studies, we began to see the emergence of what we describe as the participatory archive. Schnapp (2008: para.1) argues that while the word 'archive' typically 'connotes a past that is dead, that has severed its ties with the present, and that has entered the crypt of history', the notion of participatory archiving opens up the potential to 'animate' the archive, to bring it to life, through the participation, for example, of the creators and users of the artifacts, in designing the archive, as well as in coding and recoding the data.

\section{Participatory cultures and a case for re-coding and re-mixing}

2.7 Jenkins et al. (2006:7) refer to participatory cultures as being characterised by the following: (1) 'There are relatively low barriers to artistic expression and civic engagement.' Thus, everyone can participate and produce. Participation does not rest on expertise. (2) 'There is strong support for creating and sharing what you create with others'. Audience, and some sort of public display or outlet is important. (3) There is often some kind of informal mentorship whereby what is known by the most experienced gets passed along to newbies and novices'. This validates collaborative (and hence noncompetitive) community work. (4) 'Members feel that their contributions matter.' The issues and themes that participants take up are important to them. And finally, (5) 'Members feel some degree of social connection with each other at least to the degree to which they care what other people think about what they have created'. This last point simply corroborates the significance of choice, ownership, community and public engagement. Participatory cultures thus point to affiliations (memberships, formal and informal, in online communities centered around various forms of media), expressions (producing new creative forms), collaborative problem-solving (working together in teams, formal and informal, to complete tasks and develop new knowledge) and circulations (shaping the flow of media).

2.8 Jenkins et al. (2006) refer to a growing body of scholarship which suggests the value of participatory cultures in allowing participants (they typically speak of youth) to learn from each other while simultaneously preparing themselves for the world of work and citizenship. A key component of this work is based on the idea of re-mix. 'The concept of "remix" refers to a broad set of social and cultural practices consisting of the fragmentation, re-ordering, and recontextualisation of both pre-existing and new content - whether text, sound or image' (What is remix? n.d.). At a recent conference on $\mathrm{DIY}^{[4]}$ the creative possibilities for the use of digital media (and other artistic forms) to put together texts in new ways were highlighted, with Facebook being a good example of how participants re-use and re-work image and sound. At another recent event, the Remix Cinema Workshop ${ }^{[5]}$, which specifically focused on re-mix and the use of remixing practices by young people working with video archival data (Remix Cinema Workshop n.d.), some of the legal issues of working creatively with these texts were considered.

2.9 In the next section we describe a participatory archiving workshop conducted with community health workers, reusing (re-coding) the photo data produced in the community by young people 5 years earlier.

\section{The study}

3.1 We were interested in the 'how' (the process) of the community health workers engaging with the data itself, and what we might learn about participatory analysis by working with this group. At the same time we were interested in how they would see the issues of stigma (the captions in the re-coding), given that the photos had been produced five years earlier, what might they have to say about the ways that stigma might have changed?

\section{The participants}

3.2 The 13 community health workers (12 females and one male, ages ranging from 25 to 44), many of whom we had worked with since the first project's inception in 2004, participated in the re-coding and re-analysing of the photographs in the digital archive. Community health workers are typically lay workers within the health profession. The term community health worker (CHW), according to Schneider et al. (2008:180), is a concept which has been used internationally for many years, and which was introduced in South Africa as 'the umbrella concept for all the community/lay workers in the health sector' at a time when addressing the HIV and AIDS epidemic was prioritised. Community health workers then are local community members who are given limited training in basic health services, and who then provide such services to the members of their local communities (Berman et al. 1987). In 2004 there were an estimated 40000 lay health workers working in South Africa (NDoH 2004) contributing to primary health care. An interesting debate, of importance to us as educational researchers, is 'whether they were [are] to be viewed as agents of community empowerment or narrow functionaries of the health system' (Schneider et al. 2008:180). We view both as equally important and hence our work around HIV and AIDS and stigma with the community health workers also aims to 'empower' the community with a deeper understanding of stigma and its impact on the community. 


\section{Methodology}

3.3 The participatory archiving workshop was divided into two main parts. The first part of the workshop focused on how community health workers visualise stigma. In so doing we provided digital cameras to the participants, and used the same prompt that we had given to the learners five years earlier. In asking the community health workers to follow the same prompt, we thought that they would become engaged in thinking about stigma in the community through their own photos. We also wanted to use the opportunity to introduce the idea of visual ethics in relation to digital archiving. In the second part of the workshop, the participants worked with the archival materials.

3.4 The process of working with the archive began with introducing the archive to the community health workers and in particular giving them an opportunity to scroll through it so that they could get an overview of all the photographs in the collection. It was important for them to see what the postings looked like and also the ways in which the images already had captions produced by the students.

\section{Community Health Workers using the digital archive}

3.5 The next step was to introduce them to the idea of participatory coding through the process of developing their own captions. To do this we printed a selected set of photographs from the archive but left out the captions which the learners had created in the first place. The participants worked in pairs or trios to begin to code the visual data. We asked them to select 3 to 4 photographs which they thought they could work with, and then to discuss the meaning each photograph had for them. Creating such captioning draws on the example of Norfleet (2001 cited in Harper 2008:197), possibly 'the first practicing visual sociologist' according to Harper, who used archived photographs documenting everyday life from the 1950 's and then added captions from popular sociological texts of the time, becoming the basis for a sociological analysis of everyday life.

3.6 They then wrote their own captions for the images. We wanted the community health workers to express themselves in the language they felt comfortable with, and therefore some captions are presented in isiZulu followed by an English 
translation. Considering the time which had elapsed since the earlier work around stigma with the learners, viewing the photographs helped the community health workers to recall the photovoice study in which they themselves had participated along with the teachers. Like Harper (2008:199) we found the photographs were able 'to stimulate memories that word-based interviewing' did not do and that one gets more than just a description, as the photographs can elicit meaning as experienced by the participants. Twenty photographs were re-analysed and captioned in this way.

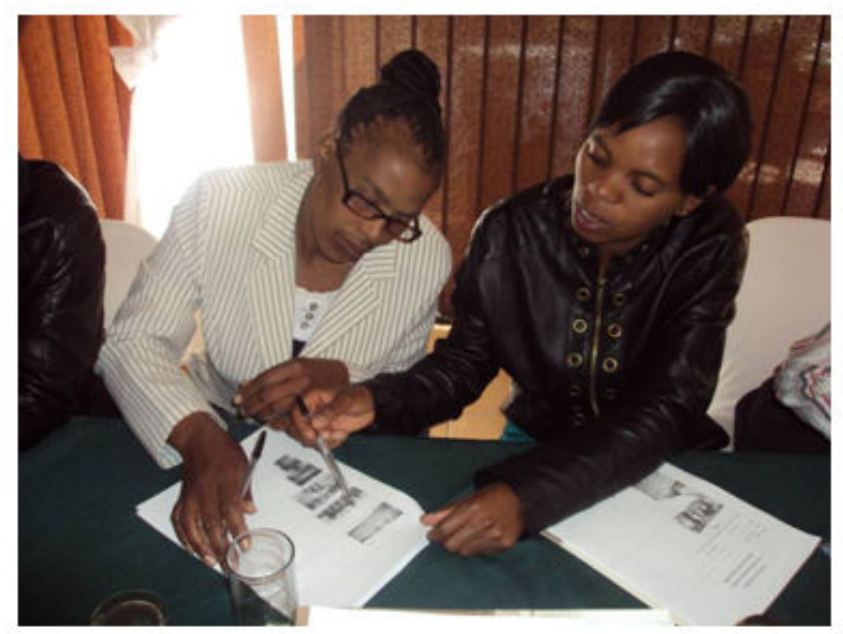

Figure 2. Looking at looking: Two community health workers re-coding archived visual data

3.7 After completing their coding, the participants were asked to comment on the process and in relation to questions such as the following: What did you like best about working with the photos of stigma taken by the learners five years ago? What did you learn about stigma from working with the sets of photos? How could you use these photos in your work as a community health worker?

\section{Analysis}

3.8 As noted above, the original captions were produced by the students who had created the data, (i.e. the photographs of stigma), and through re-coding, the community health workers, as 'experts' from the community (Shilton and Srinivasan 2008), added their own captions or tags to the visual data. We were also interested in the participants' responses to working with the digital archive and how they thought they could use the digitised photographs and digital archive in their work in the community. We focus here first on the overall response of the $\mathrm{CHW}$ to engaging in this kind of work and then look at several examples of their coding.

\section{Working the archive: Findings}

4.1 The day to day work of community health workers in a rural setting is typically a situation 'of going house to house caring for the sick' (interview with a community health care worker in the video, Our Photos Our Videos, Our Stories (Mak, Mitchell and Stuart 2005)), and does not involve working with coding visual data in a workshop setting. However, the local clinic to which they are attached does offer regular training sessions on, for example, the practice of taking sexual histories, so although the activity of engaging in participatory analysis may have been quite new to the participants, a day of professional development was not. The activity of working with the archive probably fits more within professional development. We mention this as a way of framing the interest and enthusiasm of the 13 participants in relation to the activity of scrolling through the digital archive and then working in pairs to code the images. It is also worth noting that they were working with images of very familiar settings such as the local schools, and as such they were engaged in looking closely at the pictures. As we note elsewhere (Mitchell 2011; Pithouse and Mitchell 2007), looking at looking is itself a component of visual research (See Figure 2).

4.2 In the examples below we include first the original captions produced by the students who took the pictures in the first place (caption 0), followed by the captions produced by the community health workers in the participatory archiving workshop (caption 1, 2...). For the purposes of highlighting different issues, we as the researchers have offered a thematic title for each image.

\section{Persisting gender inequality increases women and girls' vulnerability}




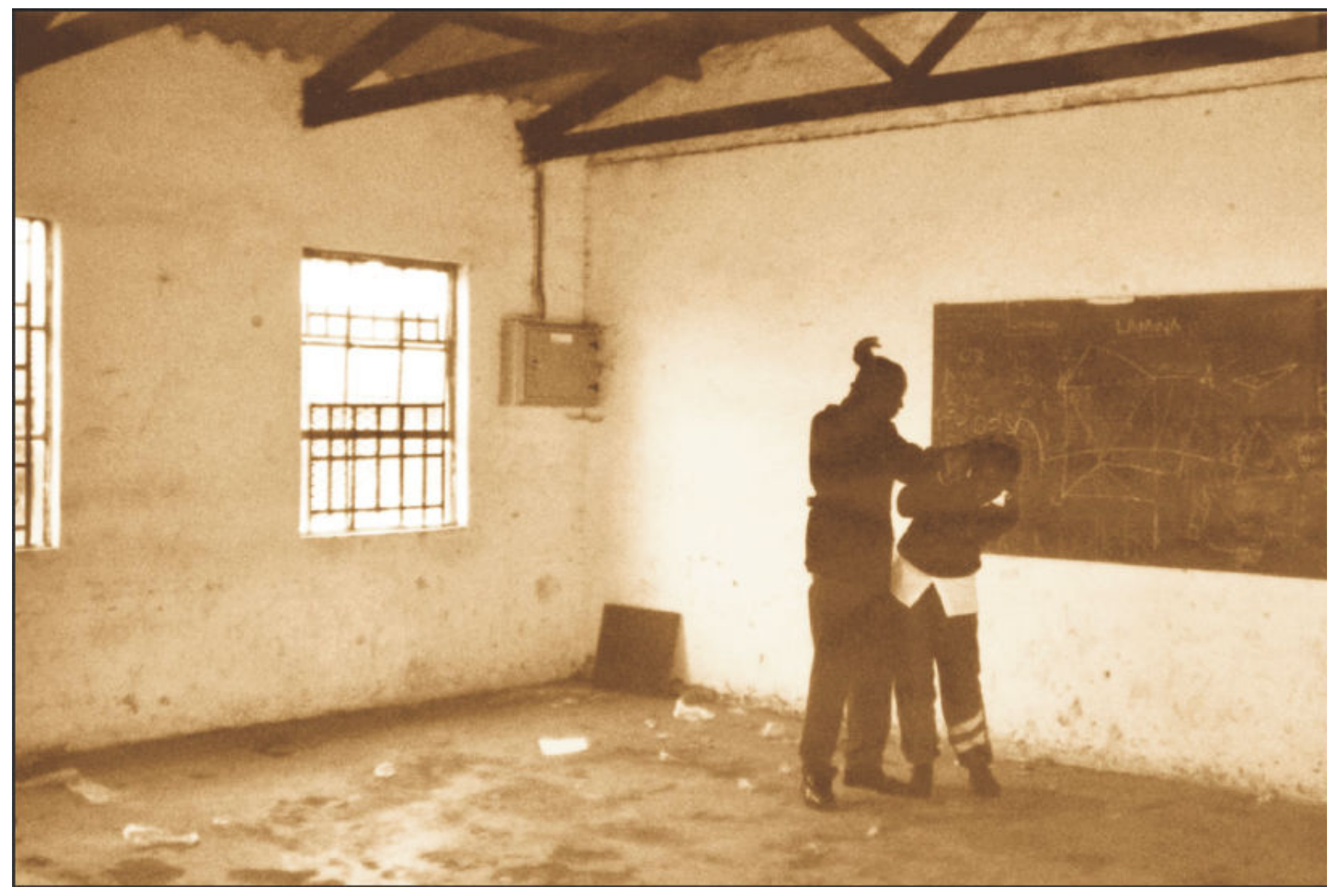

Figure 3. A photograph of a boy hitting a girl

Caption 0: I took this picture because I think he is hating his wife because he doesn't need her any more because she got AIDS.

Caption 1: iboyfriend ishaya igirlfriend ngoba ithole ukuthi iHIV positive izitshela ukuthi iyithole kuyona. (A boyfriend is beating his girlfriend because he discovered that he is HIV positive, he believes he was infected by the girl).

Caption 2: useyamshaya akufuni ukwa mukela. Intombi itshela umafana ukuthi upositive. (He is beating her. He does not want to accept when the girlfriend discloses her [HIV] status).

Caption 3: Ngicabanga engathi lapha lona omunye ushaya lona ngoba emtshele ukuthi uHIV manje sebeyalwa. (I think this one [boy] is beating the other [girl] because she disclosed her [HIV] status, and they are fighting about that).

Caption 4: Fighting each other... Because they don't want to visit or having sex with his [her] boyfriend. Domestic.

4.3 The original caption highlights the perception that women and girls are spreading HIV, and that they could be beaten for doing so, and then discarded because 'he doesn't need her any more'. This caption does not entertain the possibility that the man could have infected the woman. Not knowing their status means that one or both of the partners could continue spreading the virus. The caption also raises the challenge of disclosure in a community where women are socioeconomically disempowered, which contributes to their vulnerability and higher infection rates (Amnesty International 2008). The captions produced by the community health workers suggest that they too see that women are spreading the virus and the epidemic. Furthermore, their captions highlight the idea that disclosing has violent repercussions for women. The stigmatising effect of HIV and AIDS contributes to the vulnerability of women, already in a vulnerable position because they are women.

\section{Knowing your status}




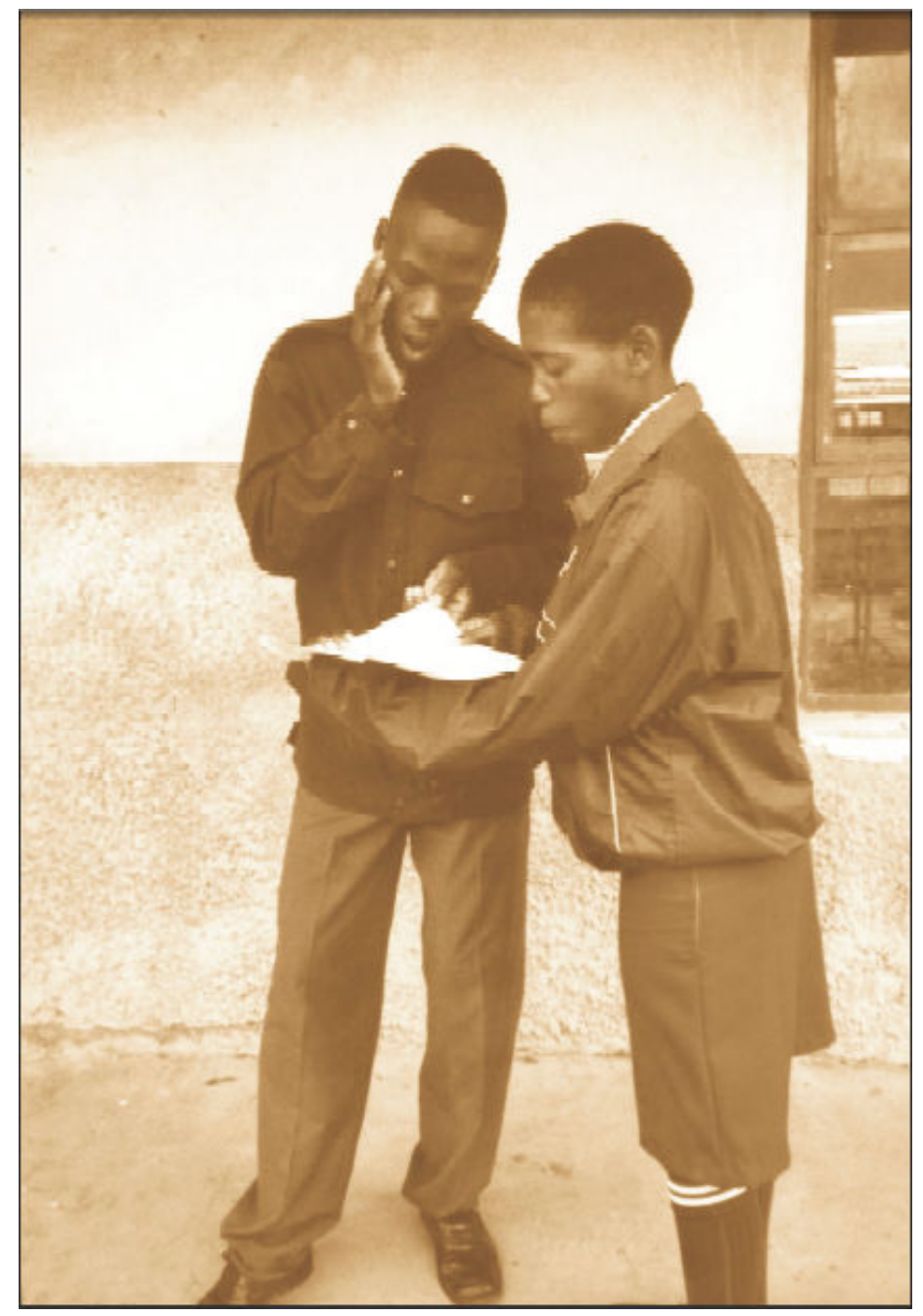

Figure 4. A girl sharing her test results with a boy

Caption 0: Losisi uhambile wayohlola wathola ukuthi une HIV manje sebephatheke kabi. (The female went for an HIV test and discovered that she was HIV positive and now they are both depressed.)

Caption 1: Lona umtshengisa ama imphumela yakhe awuthole eclinic uyamanga lo nge mphumela. (This one is showing her results from the clinic and the other is surprised about the results).

Caption 2: Umkhombisa ama-results akhe kade ehlolile, kade ese elumi manjo uyamanyela, uyesaba. (She is showing her results after examining it, now she is anxious and afraid). 
4.4 The original caption points to the girl being tested with the results indicating that she is HIV positive. The caption also refers to talking about the results with someone who possibly is her partner. The students' caption refers to both partners being depressed, while the CHW's captions refer to 'being surprised' and 'anxious' and 'afraid'. While receiving such results would evoke various feelings, the 'being surprised' could also point to a lack of sound knowledge about how HIV is transmitted, to the youth not believing themselves to be at risk, and to the possibility of partner infidelity. Anxiety and fear could point to the unknown trajectory of AIDS as an illness, still not knowing that AIDS is a treatable and manageable disease, and not knowing how disclosing to a community would be received.

\section{To tell or not to tell}

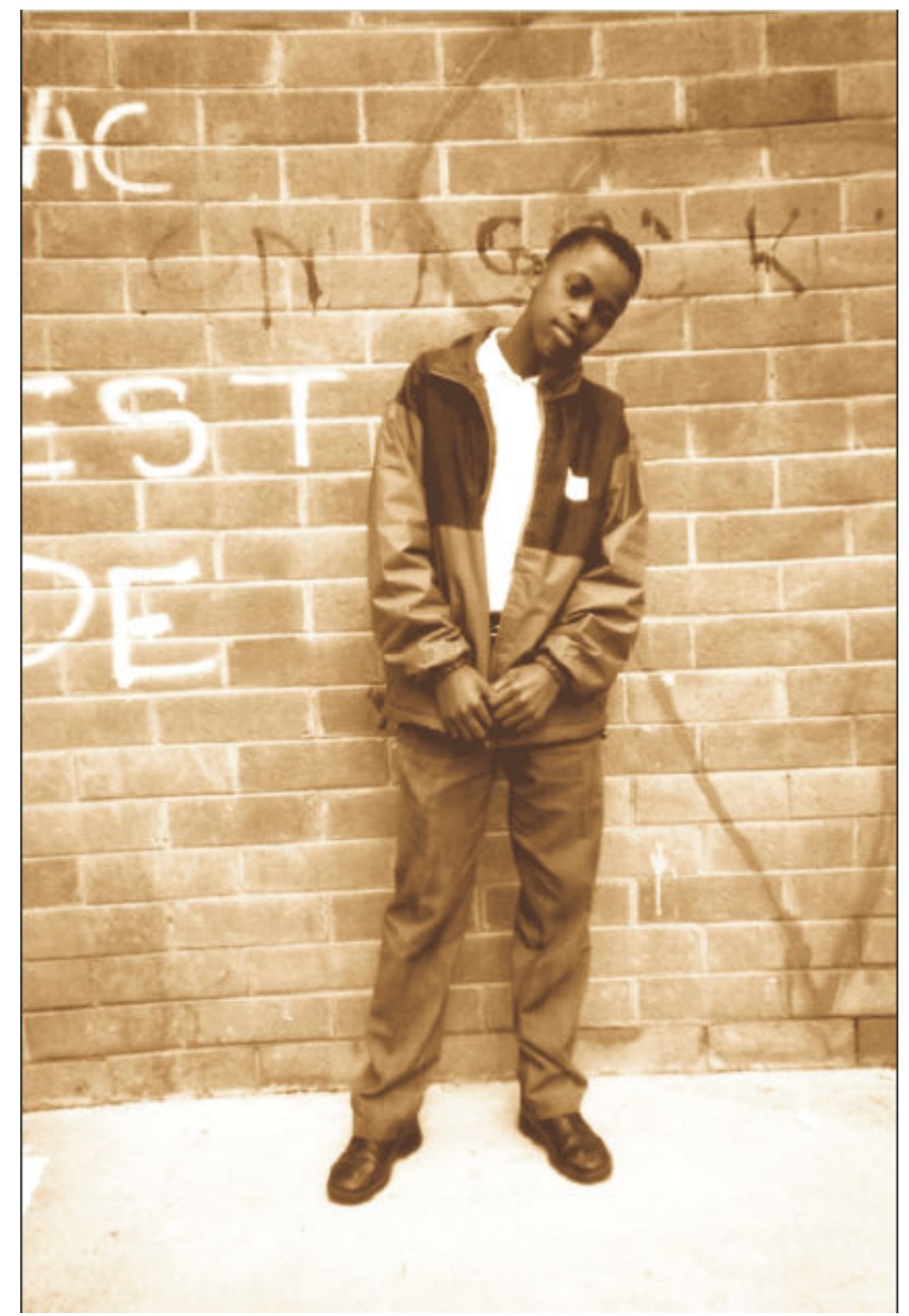

Figure 5. A boy unable to tell of his status

Caption 0: 'Ngithi angikhulume ngalesi sithombe ngoba ngibona ukuthi umthetho wakhe uphatheke kabifuthi akamboni umuntu angakhuluma naye abona ukuthi angamsiza kulenkinga anayo. Manje ubona ukuthi akaselutho emhlabeni ngoba unenkinga angeke akwazi ukusthela umuntu ukuthi uHIV positive ngoba ubona ukuthi u HIV positive ngoba ubona ukuthi bazomhleka emphakathini'. (I have selected this picture because I can see there is no joy in this boy and he does not have anyone to share his problems with. He lost hope for life after he discovered that he was HIV positive and he could not tell anyone because he thought people won't show empathy).

Caption 1: Lomfana ucabanga ngaba mcwasayo esikoleni njengoba etshele abangani bakhe ukhuthi abazali bakhe bamshiya epositive [HIV]. (This boy is thinking about his discriminators at school since he told his friends that his parents left him because they were positive [HIV]).

4.5 The original caption depicts hopelessness of being HIV positive, at a time when it often seemed impossible for people living with AIDS to disclose their status particularly in the context of how the community might react. The case of Gugu Dlamini, a young woman from KwaZulu-Natal, who disclosed her status and was subsequently killed (Fredriksson \& Kanabus 2008) is regarded as a key example of what could happen. The caption also implies the silence around HIV and AIDS which leaves people ignorant about the pandemic, fuels discrimination and stigmatisation, and ensures an absence of empathy, care and support for PLWA. The caption produced by a CHW highlights the ways in which children are often stigmatised because of their parents' HIV positive status. While this underscores the fact that stigmatisation is still alive in the community, it also points to the fact that children of infected parents are discriminated against and often left to fend 
for themselves. At the same time, it also points to the significance of being able to tell one's friends in the hope of gaining acceptance and understanding.

\section{Rather die than tell and be ridiculed}

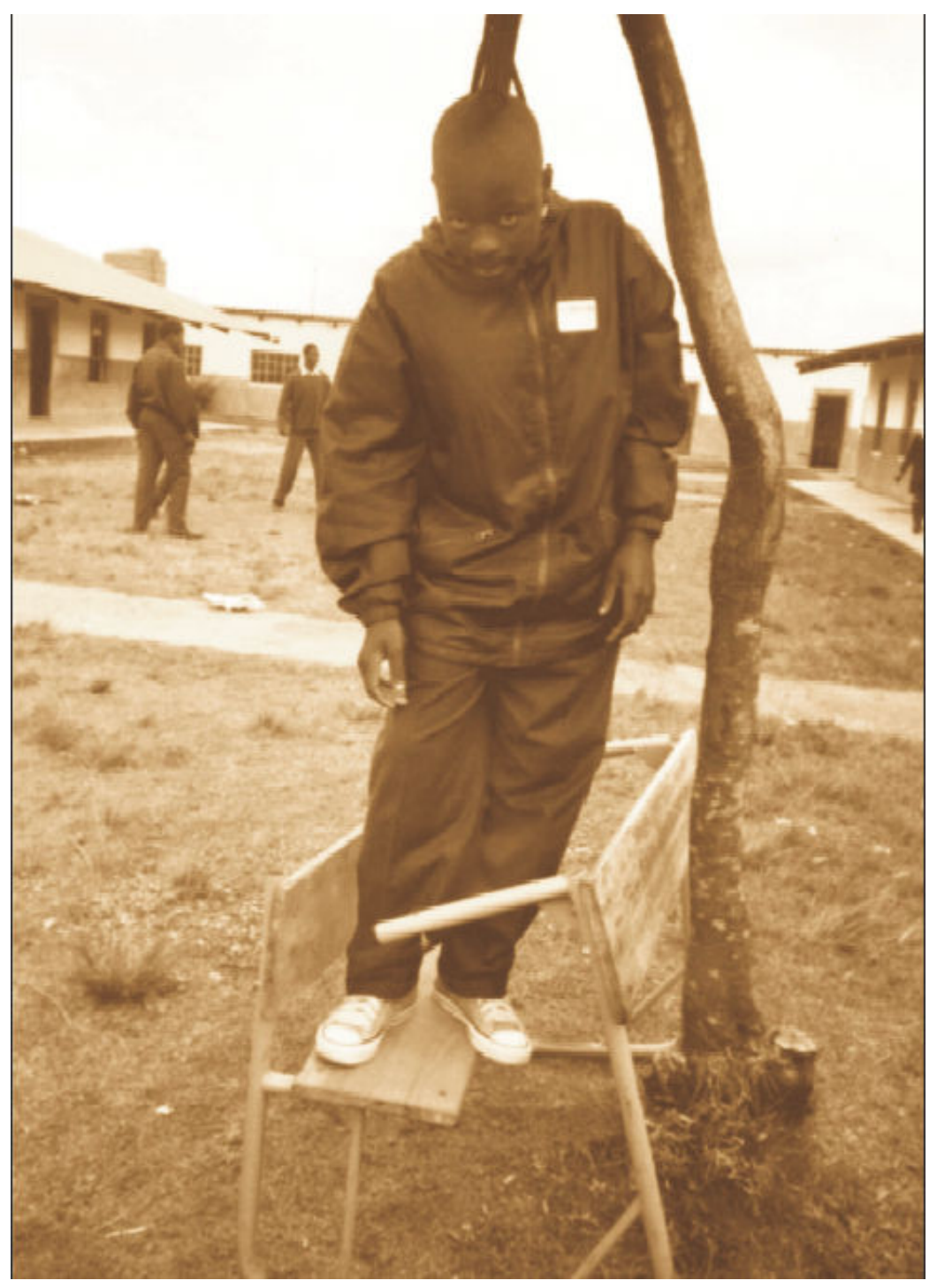


Figure 6 . A boy staging a suicide

Caption 0: Akakwamakeli ukuthi une HIV/AIDS. Ubona ukuthi azibulalae ngoba akathandi ukutshela abantu ukuthi une HIV. (He could not accept that he is HIV positive he decided to commit suicide because he does not want to reveal to other people that he is HIV positive).

\section{Caption 1: Committing suicide}

Caption 2: Isolated. This guy is trying to kill himself because every time he sees his friends they just laugh at him, because of his status.

4.6 The original caption speaks to a time when disclosing one's status was not considered an option and when suicide was the only way out (Booi et al. 2009). The later caption speaks to the rejection experienced from friends, who ought to have been supportive (Campbell 2003). In spite of a clearer understanding of HIV and AIDS, AIDS and stigma are still considered equally dangerous.

\section{Youth reaching out in support of each other}

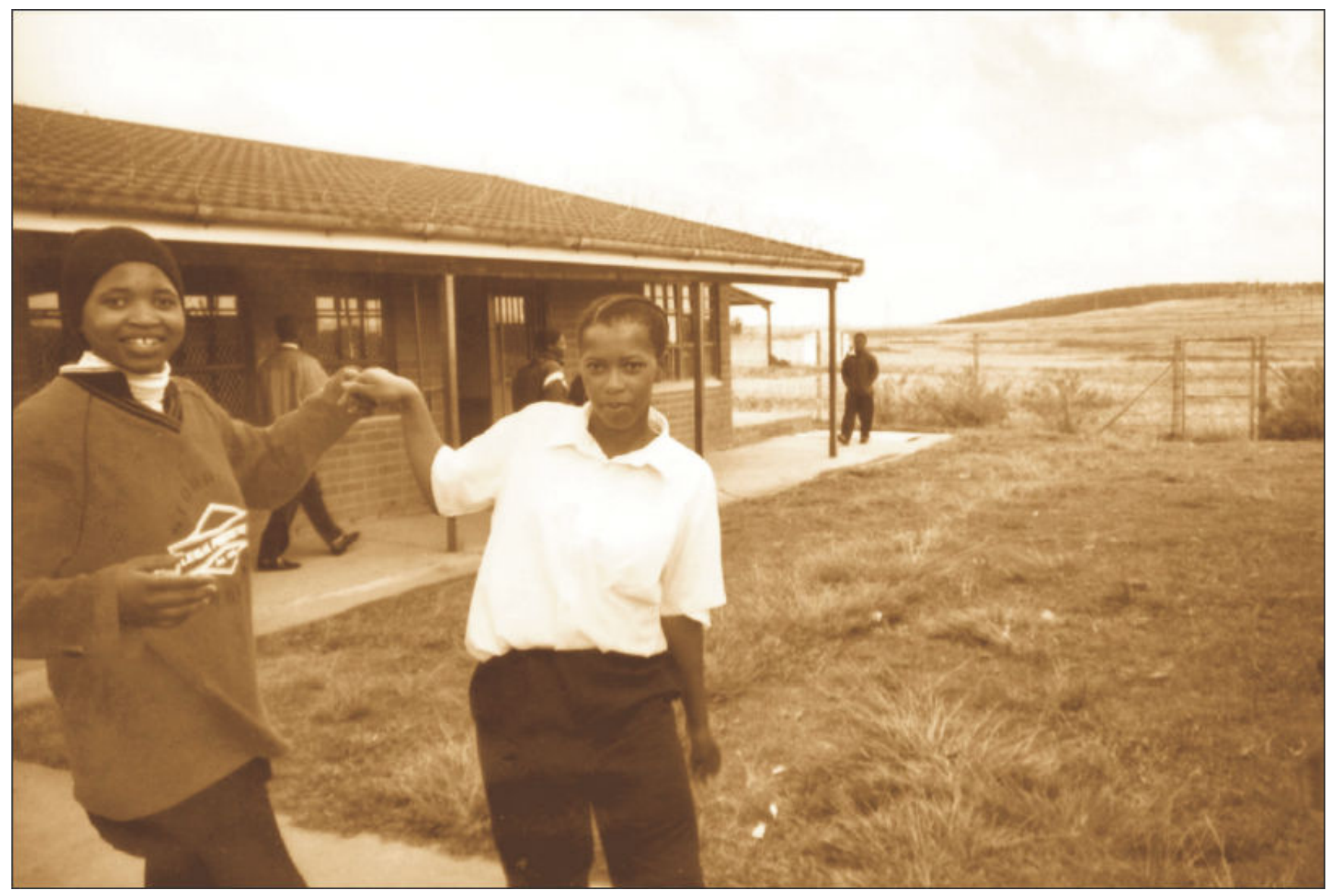

Figure 7. Two girls, one supporting her HIV positive friend

Caption 0: 'Lamantomhazane eyodwa le engakaright inegciwane le HIV kodwa umgani wayo akayicwasi uyayithanda '. (These two girls are friends and the one on the right hand side is HIV positive but her friend still loves her).

Caption 1: Lapha abacwasani lona omunye umtshelile ukuthi upositive kodwa ukwamukele lokho uyakwazi ukuba adlale naye akhululeke. (They are not discriminating, the other one has disclosed that she is HIV positive but they still play together freely).

4.7 Both captions point to youth, acknowledged as a high risk population (Motsoaledi 2009) who engage in risky behaviour, but who, in the photograph, also demonstrate the possibility of being able to reach out in support of each other.

\section{Studying the process of re-coding}

4.8 These five examples demonstrate how community health workers participated in 'working the archive' by re-coding the photographs through reflection on the images and addition of new captions, in order to contribute to deepening an understanding of stigma in the community. As noted earlier, we were also interested in whether they would perhaps see 
changes in how stigma is experienced. While their re-codings do not show that there has been a clear shift in how community members are seeing stigma (both in relation to vantage point and time), it was interesting to note that the community health workers nonetheless pointed to changes in the impact of stigma over the five years. Furthermore, when asked what they liked about working with the photographs made by the learners five years earlier, the community health workers offered the following comments:

'I was impressed because there is a big difference between what happened in 2005 and now'.

'It taught me that there is a change by that now people know better than before'.

'It's the fact that they show us what used to happen all those years ago, and now looking at the ones of the current years, we get to understand what happens in this world.'

4.9 We also asked what they had learnt about stigma - by working with the archive - and they pointed to the relevance of the data, and acknowledged that stigma was and still is 'the burning issue[s] in the society'. They also saw, maybe for the first time, that the learners - the youth whom they work with - have a clear sense of the injustice of stigmatising and discrimination, and that as such community health workers and youth could actually be allies,

'It shows that even learners can see that stigmatising is not a good thing' when 'working tirelessly to teach people to accept people and not to stigmatise them.'

4.10 Considering the purpose of the digital archive, we also wanted to know how they might use the digital archive, which they themselves had contributed to through their re-coding. They offered some obvious points, such as the following:

'I will use them to show the community how bad it is to stigmatise people'

4.11 However, the participants also showed an understanding of the need for participatory engagement from the community, by saying,

'I will use them to teach the society by showing them the pictures and they will have to say what they mean to them'.

4.12 These examples can be read as instances of re-coding and re-using, and point to some of the possibilities for positioning the work of participatory archiving/participatory analysis within an emerging participatory cultures framework, one which places at the centre the idea of creative 're-mixing' in working with digital media.

\section{Discussion}

5.1 It may on the surface seem like a giant leap to move from the winding and often dusty roads of rural KwaZulu-Natal where the workshop took place to the seemingly high tech, urban world of re-mix and DIY (Do-it Yourself) culture. But it is the same setting that appeared on the front page of the New York Times (2010), announcing the medical breakthrough related to microbicide testing and rural women's access to some control in their sexual lives in relation to HIV and AIDS. Technology is changing the landscape of HIV and AIDS, and so we think it interesting to think of the re-mix work of the community health workers as part of a participatory cultures world.

5.2 The work that we describe here with the community health workers in one district is far from done and the idea of a community-based democratic archive remains to be fully realised. However, by positioning this work within a participatory cultures framework, one that is particularly relevant to the lives of young people (including rural young people) and their interests in the internet and mobile phones ${ }^{[6]}$, we envision the digital archive as a potential participatory tool in itself.

5.3 In the examples taken from our participatory archiving workshop with the community health workers, re-mix is limited primarily to the idea of re-coding through re-using data. Nonetheless, working with the images in creative and analytical ways that are new, has the potential to change the power dynamics of who manages local knowledge. What this work speaks to ultimately, we would argue, is locating participatory visual methodologies such as photography/photovoice, participatory video, and participatory analysis in community-based research within the bigger picture of participatory cultures. In the examples of re-mix through re-coding, we see the possibility of shifting engagement with critical issues related to HIV and AIDS from being focused solely on individual expression to community involvement (Jenkins et al. 2006). How might participants - adults, in this case, as well as youth themselves - become agents in the construction of knowledge through participatory archiving? Locating this work within the broader area of Social Anthropology, Information Technology, Engineering, and Computer Science, and drawing on such interactive visual approaches as digital storytelling, setting up wikis, and gaming, we ask what would happen in this era of the popularisation of digital technology if participants could 'play' in an interactive and dynamic way with their own visual data through re-mixing and re-storying, as reflected in Jenkins' (2006) notion of convergence through participatory culture? In his book Convergence, he looks at the significance of interactivity and participation within a Web 2.0 culture, noting the ways in which digital technologies - video, flickr, mobile phones, webcams, blogs, wikis, and bulletin boards - 'converge' and also how they contribute to expanding the notion of a 'participatory cultures' framework.

5.4 This work suggests uses for social media that seem particularly in keeping with the new digital landscape of South 
Africa. In the rural area where the work we describe here is undertaken, not all youth, teachers and community health workers, of course, have access to technology, and therefore the 'participation gap' that Jenkins et al. (2006) refer to also applies to this context. However, this is changing and while previous internet spaces only allowed for the location of information (Curry 2010), the current wave of connectedness made possible through the widespread (geographical) access to cellphone and computer technologies, allows these media to be used in a socially interactive way, opening up the possibility of it being used to address a variety of issues including HIV and AIDS (AIDS*Gov 2011). And while, as Labacher (2011) observes, the most effective uses of social media in the context of HIV and AIDS remain to be seen, clearly social media are already occupying a significant space in South Africa. Access to cellphone technology and social media could be seen as the basis for engaging youth and adults working with youth (e.g. teachers and community health workers) through the use of digital media such as digital archives containing photographs to address issues such as stigma.

"One of the most difficult issues faced by social scientists and journalists who do sociological research" writes Duneier (2001:353) "is the question of when it is appropriate to intervene in the lives of the people they write about".

5.5 Without question the participatory archiving workshop was an intervention in that the participants would have otherwise been unlikely to embark upon re-coding of the students' photo images of stigma. The use of participatory archiving/participatory analysis, we argue, has value to continually extend the work with members of the community, including teachers and community health workers, through a process which highlights the significance of a 're-coding, reusing and re-mixing' approach to knowledge production. The participatory digital archive, as a collection of records in digital form, not only documents the past and allows a look back over time, but also, we speculate, encourages current and future participants to revise the community narratives of, in this instance, stigma over a period of time. This also implies that the participatory archive, its content, use and re-mixing belongs to the community and is not simply researcher-focused. There are of course many issues to be considered, and we see more work to be done in this area.

5.6 Byrne et al. (2009) acknowledge that there are few examples where research participants are involved in participatory interpretation and analysis of data, and caution that difficulties of credibility could arise. We do not see that the participatory archive replaces other forms of analysis so much as that as an intervention, it provides the possibility for an additional layer of analysis within social research that seeks to be participatory. Clearly, there are issues of ownership and who has access to the archive. Do images stay in an archive for all time? Who monitors how community archives are used? What education will research ethics boards require in order to consider the ethical issues related to community-based archives? How do we as researchers need to become involved as social activists in advocating for setting up community archives? These are all questions that are fuelled by the emergence of a participatory cultures framework and that speak to new possibilities for what might be described, according to Johnston (cited in Shilton and Srinivasan 2008), as archival activism. In so doing, they speak to the potential for shifting the boundaries of knowledge.

\section{Acknowledgements}

This work is based on research supported by the National Research Foundation (South Africa) and the Social Sciences and Humanities Research Council (Canada). Any opinion, findings, conclusions or recommendations expressed in this material are those of the authors and therefore the NRF nor the SSHRC do not accept any liability in regard thereto.

\section{Notes}

1 Since 2004, our work in this community has been supported by a number of NRF and SSHRC funded studies: Learning Together (PI Naydene De Lange; Every Voice Counts (PI Naydene De Lange); Seeing for Ourselves (PI Claudia Mitchell); Nothing About Us Without Us (PI Relebohile Moletsane).

${ }^{2}$ We followed the work of Caroline Wang (1999) who coined the term photovoice to describe the process of giving cameras to community members in documenting their everyday lives.

3 In this case a collection of more than 500 photographs was generated in the Learning Together project using photovoice - working with teachers, community health workers, parents and learners - to address issues around HIV and AIDS (De Lange et al. 2003) in a rural community. In order to store, manage and re-use the visual data, we designed another project, Digitizing data: How can we give 'life' to data to 'save' lives in the age of AIDS? (De Lange et al. 2007) in which a protocol was piloted and refined for saving, managing and re-using data, and making it accessible, in a digital archive, to researchers, community members and teachers. Ethical clearance for the research project, Digitizing data: How can we give life (to data) to save life (in the age of HIV and AIDS)? was approved in November 2008.

${ }^{4}$ DIY Citizenship: Critical Making and Social Media International Conference, held at University of Toronto, Toronto, Canada, 12-14 November, 2010.

5 Re-mix Cinema Workshop, held at, University of Oxford, UK, $24-25$ April, 2011 . Retrieved from

<http://remixcinema.org/practices-and-challenges-in-re-using-archival-video-materials/> on 3 June, 2011. 
6 South Africa has 966.1 cell phone subscribers per 1000 people, and has the third largest cell phone internet using
population in the world (Czerniewicz 2009).

\section{References}

ABDOOL KARIM, S. (2010) An overview of the HIV epidemic in sub-Saharan Africa. Paper presented at The XVIII International AIDS Conference, Vienna, Austria, 18-23 July.

AIDS*COV. (2011) Using new media tools in response to HIV and AIDS. <http://aids.gov/using-newmedia/tools/mobile/mobile-new-media-onepager.pdf $>$.

AMNESTY INTERNATIONAL. (2008) 'I am at the lowest end of all'. Rural women living with HIV face human rights abuses in South Africa. London: Amnesty International Publications.

BERMAN, PA. GWATKIN, D.R. \& BURGER, S.E. (1987) Community-based health workers: Head start or false start towards health for all? Social Science and Medicine, Vol. 25, pp. 443-59.

BHANA, D. (2008) Beyond stigma? Young children's responses to HIV and AIDS, Culture, Health \& Sexuality, Vol. 10, No. 7, pp. 725-738.

BOOI, M. NGCUKANA, L. \& PATHER, S.L. (2009) Aids rumour kills five, Sunday Times, 1 September, 2009.

$<$ http://www.timeslive.co.za/sundaytimes/article52147.ece>.

BYRNE, A. CANAVAN, J. \& MILLAR, M. (2009) Participatory research and the voice-centred relational method of data analysis: Is it worth it? International Journal of Social Research Methodology, Vol. 12, No. 1 pp. 67-77.

CAMPBELL, C. (2003) Letting them die: Why HIV/AIDS programmes fail? Oxford: James Currey.

CAMPBELL, C. SKOVDAL, M. MADANHIRE, C. MUGURUNGI, O. GREGSON, S. \& NYAMUKAPA, C. (2011) "We, the AIDS people ...": How antiretroviral therapy enables Zimbabweans living with HIV/AIDS to cope with stigma, American Journal of Public Health, Vol. 101, No. 6 pp.1004-1010.

CHITANDO, E. \& TOGARASEI, L. (2008) "Woman, where are they?" John 7:53-8:11 and stigma in the context of HIV and AIDS, Missionalia, April, 4-15.

COOMBER, R. AND SIMMONDS, L. (2009) 'Injecting drug users: A stigmatised and stigmatising population', International Journal of Drug Policy, Vol. 20, No. 2 pp.121-130.

CZERNIEWICZ, L. (2009) The fuss about cell phones, <http://blogs.uct.ac.za/blog/laura-cet/2009/09/28/the-fussabout-cell-phones $>$.

CURRY, K. (2010) Warcraft and civic education: MMORPGs as participatory cultures and how teachers can use them to improve civic education The Social Studies, Vol. 101, pp. 250-253.

DE LANGE \& MITCHELL (Forthcoming) "What happens when we're gone?" Participatory Video after leaving the field. In Milne, E.J., Mitchell, C. \& De Lange, N. (Eds.). Handbook of Participatory Video. Alta Mira Press.

DE LANGE, N. MITCHELL, C. MOLETSANE, R. STUART, J. TAYLOR, M. \& MAZIBUKO, F. (2003) Learning together. Towards an integrated participatory approach to youth, gender and HIV/Aids interventions in rural KwaZulu-Natal schools. Focus Area Proposal. National Research Foundation.

DE LANGE, N. MITCHELL, C. MOLETSANE, R. STUART, J. BUTHELEZI, T. \& TAYLOR, M. (2007) Digitization data: Giving 'life' (to data) to 'save lives' in the age of AIDS. Proposal. National Research Foundation.

DE LANGE, N. MNISI, T. MITCHELL, C. \& PARK, E. (2010) Giving life to data: University-community partnerships in addressing HIV and AIDS through building digital archives, E-learning and digital media, Vol. 7, No. 2 pp. 160-171.

DE LANGE, N. \& STUART, J. (2008) Innovative teaching strategies for HIV \& AIDS prevention and education. In Wood L. (Ed.) Dealing with HIV \& AIDS in the classroom. Cape Town: Juta. Pp. 128-148.

DLAMINI, P.S. KOHI, T.W. UYS, L.R. PHELHU, R.D. CHIRWA, M.L. NAIDOO, J.R. HOLZEMER, W.L. GREEFF , M. \& MAKOAE, L.N. (2007) Verbal and physical abuse and neglect as manifestations of HIV/AIDS stigma in five African countries, Public Health Nursing, Vol. 24, No. 5 pp. 389-399.

DUBLIN CORE METADATA INITIATIVE (2008) Dublin core metadata initiative (DCMI). [Online].

$<$ http://www.dublincore.org $>$.

DUNEIER, M. (2001) Sidewalk. New York: Farrar, Strauss \& Groux.

DRUPAL (n.d.) <http://drupal.org> 
FREDRIKSSON, J. \& KANABUS, A. (2008) HIV/AIDS discrimination and stigma. <http://www.avert.org/aidsstigma.htm>.

GILBERT, L. \& WALKER, L. (2010). 'My biggest fear was that people would reject me once they knew my status ...': stigma as experienced by patients in and HIV/AIDS clinic in Johannesburg, Health and Social Care in the Community, Vol. 18 , No. 2 pp. 139-146.

GOFFMAN, E. (1963) Stigma: Notes on the management of a spoiled identity. Englewood Cliff: Prentice-Hall.

GOODALL, J. VAN DER RIET, M. O'NEILL, V. \& KILLIAN, B. (2011) HIV and AIDS related stigma: A necessary protective mechanism for children in high exposure? South Africa Journal of Psychology, Vol. 41, No. 2 pp. 187-195.

GREEFF, M., UYS, L.R., HOLZEMER, W.L., MAKOAE, L.N., DLAMINI, P.S., KOHI, T.W., CHIRWA, M.L., NAIDOO, J.R \& PHETLHU, R.D. (2008) Experiences of HIV/AIDS stigma of persons living with HIV/AIDS and nurses involved in their care from five African countries. Africa Journal of Nursing and Midwifery, Vol. 10, No. 1 pp. 78-108.

GREENSTONE DIGITAL LIBRARY SOFTWARE. (n.d.) <http://146.230.166.222/gsdl?uq=779786812>.

HARPER, D. (2008) What's new visually? In Denzin, N. K. \& Lincoln, Y. S. (Eds.), Collecting and interpreting qualitative materials. Los Angeles, London, New Delhi and Singapore: Sage.

HARTMANN, W. SILVESTER, J. \& HAYES, P. (Eds.) (1998) The colonizing camera: Photographs in the making of Namibian history. Cape Town: University of Cape Town Press.

HOLZEMER, W.L. UYS, L. MAKOA, L. STEWART, A. PHETLHU, R. DLAMINI, P.S. GREEFF, M. KOHI, T.W. CHIRWA. M. CUCA, Y. \& NAIDOO, J. (2007) A conceptual model of HIV/AIDS stigma from five African countries, Journal of Advanced Nursing, Vol. 58, No. 6 pp. 541-551.

HUVILA, I. (2008) Participatory archive: Towards decentralized curation, radical user orientation, and broader contextualization of record management, Archival Science, Vol. 8, pp. 15-36.

JENKINS, H. (2006) Convergence culture: Where old and new media collide. New York: New York University Press.

JENKINS, H. CLINTON, K. PURUSHOTMA, R. ROBISON, A.J. \& WEIGEL, M. (2006) Confronting the challenges of participatory culture: Media education for the 21 st century. Chicago: MacArthur.

LABACHER, L. (2011) Talk or text to tell? How young people in Canada and South Africa would prefer to self-disclose their STI status to their romantic partner, friends, and parents. Unpublished Masters Dissertation. Montreal: McGill University.

MAK, M., MITCHELL, C. \& STUART, J. (2005) Our photos, our videos, our stories. Video Documentary produced by Taffeta Production, Montreal, Canada.

MITCHELL, C. (2011) Doing visual research. London: Sage.

MITCHELL, C. \& DE LANGE, N. (2011) Data collections and building a democratic archive: 'No more pictures without a context'. In Mitchell, C. Doing visual research. London: Sage. Pp. 116-134.

MITCHELL, C. MOLETSANE, R. STUART, J. BUTHELEZI, T. \& DE LANGE, N. (2005) Taking pictures, taking action! Using photovoice techniques with children, Children FIRST, Vol. 9, No. 60 pp. 27-31.

MITCHELL, C. PASCARELLA, J. DE LANGE, N. \& STUART, J. (2010) 'We wanted other people to learn from us': Girls blogging in rural South Africa in the age of AIDS. In Mazzarella, S. (Ed.) Girl Wide Web 2.0: Revising girls, the internet and the negotiation of identity. New York: Peter Lang. Pp. 161-182.

MNISI, T. (2010) Beyond visual data: How educators use metadata to help learners understand issues on HIV and AIDS stigma. Unpublished M Ed dissertation. Durban: University KwaZulu-Natal.

MNISI, T. DE LANGE, N. \& MITCHELL, C. (2010) Learning to use visual data to 'save lives' in the age of AIDS? Communitas, Vol. 15, pp. 183-202.

MOLETSANE, R. DE LANGE, N. MITCHELL, C. STUART, J. \& BUTHELEZI, T. (2007) Photo voice as an analytical and activist tool in the fight against HIV and AIDS stigma in a rural KwaZulu-Natal school, South African journal of child and adolescent mental health, Vol. 19, pp. 19-28.

MORGAN, R. KHESWA, B. \& MELETSE, J. (2009) Creating memory: Documenting and disseminating life stories of LGBTI people living with HIV. In Reddy, V. Sandfort, T. \& Rispel, S. (Eds.), From social silence to social science: Same-sex sexuality, HIV \& AIDS and gender in South Africa. Pretoria: HSRC Press. Pp. 117-125.

MOTSOALEDI, A. (2009) HIV and AIDS: Business as usual. Media Briefing, 10th November.

NDOH (NATIONAL DEPARTMENT OF HEALTH) (2004) Speech by Minister of Health, Dr Manto Tshabalala-Msimang, at the launch of the community health worker programme, 26 February, 2004. 
NEW YORK TIMES (2010) AIDS breakthrough: African study offers hope to women by helping prevent HIV, herpes, Associated Press, July $19 \mathrm{p} 1$.

PITHOUSE, K. \& MITCHELL, C (2007) Looking into change: Studying participant engagement in photovoice projects. In N. De Lange, C. Mitchell, \& J. Stuart (Eds.) Putting people in the

picture: Visual methodologies for social change Rotterdam: Sense. Pp. 141-151.

SCHNAPP, J.T. (2008) Animating the Archive. First Monday, Vol. 13, No. 8.

SCHNEIDER, H. HLOPHE, H. \& VAN RENSBURG, D. (2008) Community health workers and the response to HIV/AIDS in South Africa: Tensions and prospects, Health Policy and Planning, Vol. 23, pp. 179-187.

SEKULA, A. (1993) Reading the archive. In Wells, L. (Ed.), The photography reader. London: Routledge.

SHILTON, K. \& SRINIVASAN, R. (2008) Participatory appraisal and arrangement for multicultural archival collections.

$<$ http://rameshsrinivasan.org/wordpress/wp-content/uploads/2010/04/6-Shilton-Srinivasan-Multicultural-Archives-

final.pdf $>$.

SIMMONDS, L. \& COOMBER, R. (2009). Injecting drug users: A stigmatised and stigmatising population. International Journal of Drug Policy. Vol. 20, pp.121-130.

STEINBERG, J. (2008) The three-letter plague. Johannesburg and Cape Town: Jonathan Ball Publishers.

WHAT IS REMIX? (n.d.) <http://remixcinema.org/what-is-remix/>

WANG, C. (1999). Photovoice: A participatory action research strategy applied to women's health, Journal of women's health, No. 8 pp. 185-192.

(c) Sociological Research Online, 1996-2012 